\title{
A IMAGEM DA NEGRA E DO NEGRO EM PRODUTOS DE BELEZA E A ESTÉTICA DO RACISMO
}

Jonathas Vilas Boas de SANT'ANA ${ }^{1}$ Universidade Estadual de Goiás - UEG jonathasvilas@hotmail.com

Resumo: Este artigo tem por finalidade discutir a representação da população negra, especialmente da mulher negra, em imagens de produtos de beleza presentes em comércios do nordeste goiano. Evidencia-se que a presença de estereótipos negativos nestas imagens dissemina um imaginário racista apresentado sob a forma de uma estética racista que camufla a exclusão e normaliza a inferiorização sofrida pelos(as) negros(as) na sociedade brasileira. A análise do material imagético aponta a desvalorização estética do negro, especialmente da mulher negra, e a idealização da beleza $e$ do branqueamento a serem alcançados por meio do uso dos produtos apresentados. $O$ discurso midiático-publicitário dos produtos de beleza rememora e legitima a prática de uma ética racista construída e atuante no cotidiano. Frente a esta discussão, sugere-se que o trabalho antirracismo, feito nos diversos espaços sociais, considere o uso de estratégias para uma "descolonização estética" que empodere os sujeitos negros por meio de sua valorização estética e protagonismo na construção de uma ética da diversidade.

Palavras-chave: Estética. Racismo. Mídia. Educação. Diversidade.

\begin{abstract}
This article has for purpose discuss the representation of the black population, especially black woman, in images of beauty products present at trades of Goias northeast. Becomes evident that the presence of negative stereotypes in these images disseminates racist imagery presented in the form of a racist aesthetic that conceals the exclusion and normalizes the degradation suffered by black people in Brazilian society. The analysis of the imagetical material pointed to the aesthetic devaluation of black people, especially black woman, and an idealization of beauty and whitening to be pursued through use of the products presented. The media-advertising discourse of beauty products remembers and legitimizes the practice of a racist ethics based and active in everyday life. Facing this discussion is suggested that the antiracism work, done in different social spaces, consider using strategies for an "aesthetic decolonization" that empowers the black population by means of its aesthetic value and protagonism in the construction of an ethics of diversity.
\end{abstract}

Keywords: Aesthetics. Racism. Media. Education. Diversity.

\footnotetext{
${ }^{1}$ Mestrando do Programa de Pós-Graduação Interdisciplinar em Educação, Linguagem e Tecnologias - PPG IELT, da Universidade Estadual de Goiás. Pedagogo, 2015, UEG/GO, bolsista da Capes/DS, edital PPG-IELT/UEG № $02 / 2016$.
} 


\section{Introdução}

Hoje, expectantes das telas virtuais conectadas numa rede mundial, assistimos a episódios que questionam a ideia de que o Brasil é o pacífico paraíso da "democracia racial”. A rede mundial de computadores e a interatividade das redes sociais, em especial, possibilita a identificação cada vez maior entre as "celebridades" e seus seguidores. É neste contexto que se repetem casos de ataques racistas principalmente a mulheres negras que têm certo destaque midiático, como ocorreu a Maria Júlia Coutinho, Taís Araújo, Sheron Menezzes e Cris Viana², mulheres negras decididas a usar seus cabelos crespos como parte de suas identidades.

Mas o que difere as agressões - entoadas com força sob os rótulos "macaca", "escrava", "cabelo de Bombril", "carvão", "cotista" etc. - sofridas por estas e outras "celebridades" das ofensas repetidas diariamente sem os holofotes da mídia nos mais diversos espaços sociais? Logicamente, a única distinção é que naqueles casos o preconceito é exposto midiaticamente, enquanto aquilo que pode ser chamado "racismo nosso de cada dia" permanece enredado nas relações cotidianas, compartilhado e promovido, na maioria das vezes sem ser questionado.

Condena-se veementemente os ataques racistas às figuras públicas, mas coaduna-se com a discriminação recorrente nos corredores de escolas, nas ruas, nos quintais de casa e demais espaços não midiatizados. Quantas vezes na vida um homem negro comum (e de forma mais intensa, uma mulher negra comum), da favela à roça, já foi pejorativamente chamado(a) de "africano(a)", "macaco(a)", "cabelo ruim", "tição" e tantos outros inferiorizantes "apelidos" aparentemente engraçados e radicalmente racistas? Esta reflexão indica que as diferenças de cor/raça/etnia/cultura/estética presentes no Brasil podem implicar em conflitos estreitamente relacionados à história do país. Ao pausarem-se os velocímetros da sociedade idólatra ao lucro, fica tácito que o preconceito racial é mais subterrâneo e profundo do que se percebe na maior parte do tempo - e estamos mais envolvidos nele do que pensamos ou gostaríamos.

Nessa conjuntura, buscando compreender e enfrentar mais radicalmente a presença atravessada do racismo nas relações coloquiais, este artigo tem por finalidade discutir a representação da população negra, especialmente da mulher negra, em imagens de produtos de

2 Alguns casos tiveram maior repercussão. Uma reportagem citando-os está disponível em: <http://www.gazetaonline.com.br/_conteudo/2015/12/entretenimento/cultura_e_famosos/3917045-sheron-menezzese-vitima-de-ataques-racistas-na-internet.html> Acesso em 26 de janeiro de 2016. 
beleza presentes em comércios do nordeste goiano, evidenciando que a presença de estereótipos negativos nestas imagens dissemina um imaginário racista que normaliza a inferiorização sofrida pelos(as) negros(as) na sociedade brasileira.

Num primeiro momento, contextualiza-se a pesquisa na região nordeste de Goiás. Em seguida, dialoga-se sobre o capitalismo contemporâneo, argumentando que a imagem midiáticopublicitária exerce papel central ao difundir a visão de mundo capitalista com seus valores excludentes em diversos espaços, inclusive em comércios. Depois, problematiza-se a representação do negro na mídia, destacando em sequência a profundidade do estereótipo da desvalorização estética. Por fim, considera-se como principal estratégia de enfrentamento desta realidade uma "descolonização estética" que promova a ressignificação e empoderamento da negra e do negro e de suas imagens nesses espaços.

\section{Contexto da pesquisa}

A discussão desenrolada neste trabalho parte da pesquisa sobre "A invisibilidade do negro nos produtos culturais e a formação de um imaginário social racista" ${ }^{3}$, aprofundando-se em um ponto específico desta: o estereótipo da desvalorização estética encontrado em imagens presentes em estabelecimentos comerciais do nordeste goiano.

Além de ser geograficamente viável, a escolha por refletir sobre a representação do negro no nordeste de Goiás tem o propósito de contribuir para o desenvolvimento dos indivíduos e da sociedade regional, pois a maioria desta população é negra, potencialmente exposta aos efeitos corrosivos do racismo. A região é popularmente conhecida como "corredor da miséria", pelo baixo desenvolvimento socioeconômico e pela carência de serviços públicos de maior abrangência e qualidade 4 , embora tenha potencial natural, humano e cultural relevante, inclusive por abrigar em seu território o Quilombo Kalunga, maior comunidade remanescente de refugiados da escravidão no Brasil (BRASIL, 2001). Contribuir para a quebra de paradigmas inferiorizantes e para a promoção da autoestima dos sujeitos negros pode auxiliar no crescimento saudável da região.

\footnotetext{
${ }^{3}$ Realizada pelo autor, sob a orientação da Prof. ${ }^{a}$ Dra. Cristiane Rosa Lopes e apoiado pelo Programa de Bolsas de Iniciação Científica da Universidade Estadual de Goiás (PBIC/UEG - 2013/14), tendo como campo de pesquisa parte do nordeste goiano.

4 Algumas informações sobre o perfil socioeconômico da região estão disponíveis em: <http://www.imb.go.gov.br/pub/conj/conj3/06.htm> Acesso em 16 de setembro de 2015. 
Não sendo possível abarcar toda a dimensão regional, tomaram-se como amostras do nordeste goiano os municípios de Monte Alegre de Goiás e Campos Belos, que juntos totalizam 26.140 pessoas, das quais 20.531 são negras e 5.609 não são negras, o que, em percentual, equivale a aproximadamente $78,54 \%$ de negros (pretos e pardos) e 21,45\% de não negros (brancos, amarelos e indígenas), conforme as categorias do Instituto Brasileiro de Geografia e Estatística (IBGE, 2010a; 2010b).

Apesar de a maioria populacional do nordeste goiano pertencer à categoria negra, Lopes e Sant'Ana (2014) constataram que isso não é refletido na emissão imagética de comércios, televisão, internet e publicidade impressa disponíveis na região. Para Sant'Ana (2015, p. 49), esta pesquisa reafirmou a tendência das pesquisas na área ao revelar que "O negro figura sempre inferioridade ao branco, que é o padrão ocidental de beleza, força e inteligência”.

\section{O capitalismo contemporâneo e o papel da imagem}

Ramose (2009, p. 171) alerta sobre o risco à vida em sociedades "nas quais a veneração ao Dólar comanda a devoção, tanto de ricos como de pobres, e numa era de fundamentalismo económico em que soberania do dinheiro substituiu o ser humano como valor fundamental'. Este aviso se dá num tempo em que o direito à vida em sua multidimensionalidade nem sempre tem sido respeitado, imperando a lógica do individualismo e da inferiorização contra o "outro". São quase sempre rejeitadas as opções mais solidárias, coletivas e sustentáveis de vida.

Este é o cenário do capitalismo atual, no qual, segundo Bauman (2008), é intenso o fluxo de interesses e de um consumismo cada vez menos palpável e mais abstrato. A existência humana passa a centralizar-se num jogo de consumo simbólico, atualizando, por meio da virtualização de uma complexa lógica de poder econômico-imagético, a criação oitocentista do homo oeconomicus apresentado por Sodré (2012). Bauman (2008) assevera que o próprio homem deseja tornar-se mercadoria, o que é alavancado por meio das mídias sociais digitais.

Fica evidente que se apresenta hodiernamente uma sociedade extremamente subjetivada e simbólica. É no espaço do abstrato, do não-concreto, isto é, do imaginário, que se desenrolam mais intensamente as expansivas estruturas do capitalismo informacional-cognitivo com suas relações sutis de poder enredadas às produções midiáticas (SODRÉ, 2012). 
Nesse âmbito, Sodré (1987) discorre sobre a telerrealidade, uma convergência progressiva de todos os veículos de comunicação, sejam eles objetos, instituições ou imagens publicitárias etc. Os meios de comunicação atuam paralelamente, com a televisão, a publicidade (em seus diversos aportes), as tecnologias virtuais, os produtos mesmos etc. De acordo com Perez (2011), a estratégia midiático-publicitária se apresenta "nas embalagens, nos cartazes, folhetos, adesivos, nos livros, nos rótulos, nas roupas, nos utensílios domésticos, nos sites, nas redes sociais" (PEREZ, 2011, p. 71). Assim, é possível analisar distintos espaços de disseminação da rede midiático-publicitária e de imposição do poder capitalista, que se utilizam da imagem como ferramenta, como é o caso de estabelecimentos comerciais.

A imagem desempenha função central neste cenário, como um elemento de socialização que tenta "criar uma associação entre os produtos oferecidos e certas características socialmente desejáveis e significativas, a fim de produzir a impressão de que é possível vir a ser certo tipo de pessoa" (KELLNER, 2001, p. 318) por meio da compra do produto.

Na compreensão de Kellner (2001), a propaganda e suas imagens presentes na rede midiático-publicitária não têm o único objetivo de fazer consumir. Estas promovem, por meio de seu imperativo de signo comunicativo (SANTAELLA, 2005), uma visão de mundo específica, a saber, o caráter abstrato das relações de poder, bem como os preconceitos existentes na sociedade capitalista.

Através da convergência e redundância nos diversos meios, as imagens contribuem para a manutenção do consenso psicológico e ideológico da sociedade, produzindo sentidos nos diversos ambientes em que estão presentes. As imagens são estratégia central da publicidade, que, para Barreto (1982), age exatamente para legitimar o sistema social capitalista e os valores do individualismo, do consumismo e do sonho de fama e riqueza endossado na idolatria ao estilo de vida ocidental e no culto ao produto.

As imagens publicitárias projetam modelos a serem seguidos em termos de estilo, moda, sexualidade, comportamento social etc. Dessa forma, "levam à identificação com certas identidades e sua imitação, enquanto se evitam outras." (KELLNER, 2005, p. 330).

Isso se torna uma problemática no Brasil ao considerar as identidades alienadas nascidas da cultura colonizadora. Nos termos de Silva (2001), permaneceu a alienação do colonizador, crente 
de ser civilizador do mundo, bem como a do colonizado, massacrado psicologicamente por meio da assimilação do mito civilizador que mantém sua mente colonizada e subserviente.

É inegável que a mídia se alicerça na ideologia do branqueamento, presente no imaginário social brasileiro desde o período da escravização e fortalecido pelo medo do escurecimento populacional pós-Abolição, repercutindo na legitimação e disseminação do fenótipo branco como suprassumo humano pelos discursos midiáticos atuais. A rede midiático-publicitária reitera este ideal ao invisibilizar o negro e imprimir estereótipos sobre o mesmo. É reforçada a "branquitude normativa, na eleição do paradigma estético e formal branco como referencial, sendo os demais que se afastam dele desviantes" (OLIVEIRA, 2011 p. 34).

No tocante à representação negativa de negras e negros nas imagens, Pereira e Gomes (2001) argumentam que nem sempre os sujeitos são atingidos diretamente. Mas, ao serem representados simbolicamente em determinado espaço da ordem social, isso é aceito como fato. $\mathrm{O}$ discurso cotidiano e midiático normaliza expressões de preconceito e esta "exclusão por motivos étnicos se desdobra também na exclusão de valores culturais, de modelos fenotípicos, de estruturas de pensamento, de formas de comportamento e de bens materiais." (PEREIRA; GOMES, 2011, p. 33). Isso ocorre porque, no imaginário social, há uma síntese cristalizada de homem universal embranquecido - daí os “diferentes” tornam-se “desviantes”. Borges (2012) assevera que a mídia tem um projeto homogeneizador que estabelece o estatuto do "outro" não-branco e define um modelo de dever-ser social ocidental, retroalimentando o racismo, dada a forte presença da mídia na vida contemporânea.

\section{A estética racista em produtos de beleza}

As discussões anteriores salientam a profundidade e relevância deste trabalho, ao mesmo tempo em que possibilitam a análise qualitativa (LÜDKE e ANDRÉ, 2004) dos dados obtidos na etapa de exploração de campo no âmbito da pesquisa sobre "A invisibilidade do negro nos produtos culturais e a formação de um imaginário social racista", com dados coletados no ano de 2014. Problematizou-se, nesse processo, a invisibilização ou aparição de negras e negros nas imagens, bem como a presença de estereótipos, compreendidos a partir de Pereira (2002) e Krüger (2004) como crenças compartilhadas coletivamente, visões generalizadas, rígidas e inadequadas acerca de determinados indivíduos ou grupos. 
Dessa maneira, além de constatar a mínima representação da população negra $(7,37 \%$ de 6845 figuras humanas), foi possível categorizar 11 diferentes tipos de estereótipos negativos presentes nas imagens em que a negra ou o negro apareciam. Tais estereótipos estiveram, por vezes, sobrepostos uns aos outros na mesma imagem, como apontam Lopes e Sant'Ana (2014).

Neste momento, interessa discutir - no sentido de "compreender para transformar" (FREIRE, 2014) - o estereótipo da desvalorização estética, que se apresentou em produtos de beleza afixados nos estabelecimentos comerciais explorados, por pelo menos três motivos: 1) os comércios do nordeste goiano são locais públicos frequentados por uma maioria populacional negra, podendo o estereótipo difundido influenciar o imaginário social, isto é, as representações sociais de negros e não-negros, calcificando a crença de que a pessoa negra é inferior; 2) o estereótipo da desvalorização estética esconde uma naturalização histórico-social compartilhada da ideia de que a mulher negra é inferior, ainda mais que o homem negro, dadas as suas características estéticas distintas de um padrão feminino branqueado; 3) a inferiorização de negras e negros "justificada" por suas diferenças estéticas é uma das demonstrações mais cotidianas e repetitivas do camuflado e negado "racismo nosso de cada dia".

\section{O estereótipo da desvalorização estética e seus sentidos}

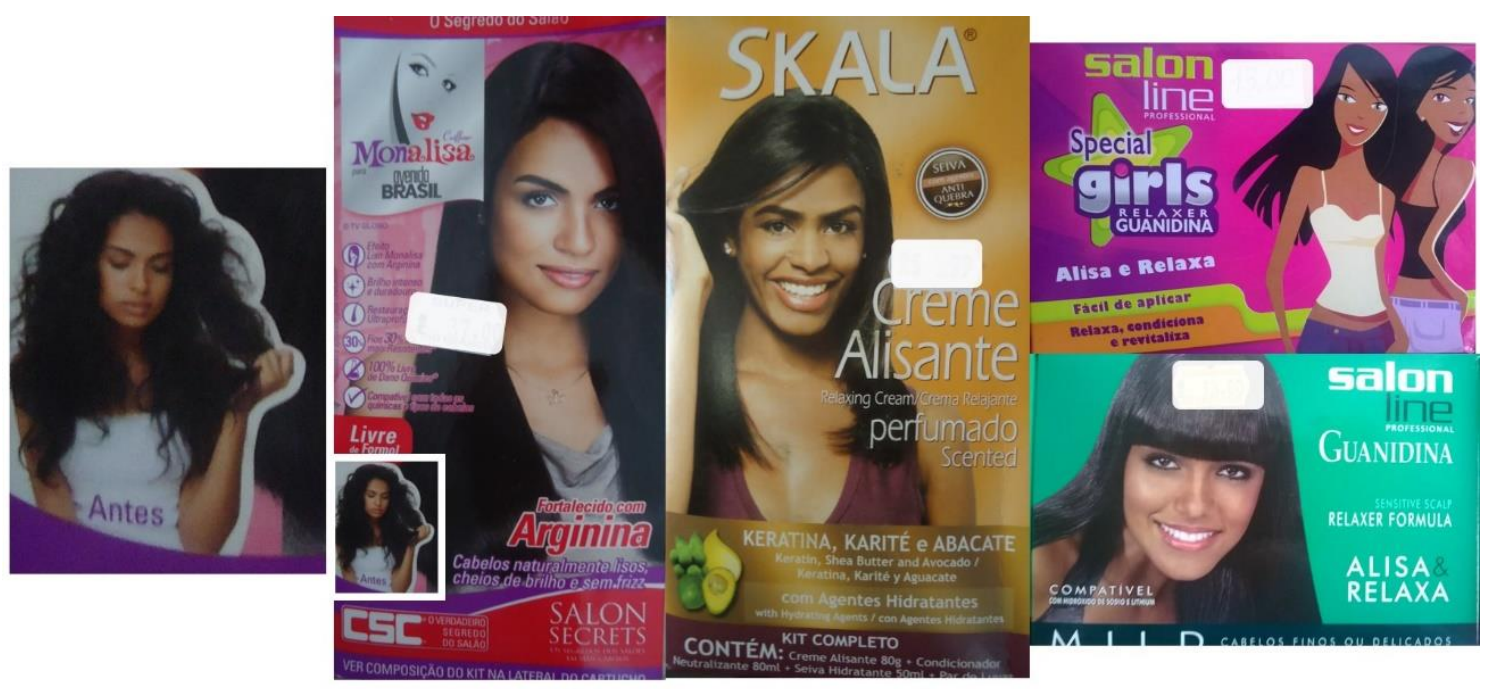

Figura 1 -Produtos de beleza em que há a desvalorização estética da negra 
No estereótipo da desvalorização estética do negro ${ }^{5}$, há a negativação da estética do sujeito afrodescendente - em especial da mulher - em termos de moda, estética e beleza (OLIVEIRA, 2011), principalmente no que se refere aos produtos de beleza para os cabelos (GOMES, 2008). Este estereótipo carrega sentidos que serão aqui analisados.

Diversos produtos destinados ao cuidado capilar, como ilustra a Figura 1, transmitem a promessa de que a mulher negra se tornará bela desde que e apenas se "cuidar" de seus cabelos com os produtos oferecidos para alisamento e relaxamento. Somente com o uso do produto é que a negra pode aproximar-se do ideal de beleza branco, assemelhando seu cabelo "ruim" ao cabelo "bom" e branqueando-se por meio dele, isto é, aproximando-se do conceito "superior" de cabelo, o liso, característico do fenótipo branco.

As embalagens de alguns produtos, como o destacado na Figura 1, mostram o "antes e depois" do uso, marcando nas expressões faciais produzidas a infelicidade e a decepção com o cabelo crespo e a felicidade e o alívio após o alisamento do mesmo. A diferença natural do cabelo crespo é tornada em inferioridade estética com valor moral (cabelo ruim), o que reforça os discursos sociais. Nega-se a possibilidade de ter cuidados capilares que valorizem o cabelo crespo; este é sempre "ruim", precisa de um produto que o relaxe e alise. Julga-se moralmente a estética do sujeito, pressionando-o para baixo por não poder se desfazer de seu cabelo.

No entanto, a questão da desvalorização estética apontada no estereótipo encontrado durante a pesquisa é parte de um enorme iceberg, em que há outras questões ligadas à inferiorização corpórea e política do negro na sociedade brasileira. O corpo do negro e da negra é estigmatizado desde o colonialismo, como se a diferença equivalesse à inferioridade.

Na literatura, um dos primeiros meios de produção ficcional de imagens e imaginário, a figura do negro foi, desde o escravismo, representada como um desvio do superior modelo branco. Moura (1988) afirma que eram raras as aparições do negro na literatura difundida no Brasil colonial, e, quando ocorriam, tinham por objetivo negar a existência do mesmo.

Os padrões brancos eram exaltados por meio da literatura; o índio tornado europeizado, romântico, diferente e superior ao negro, numa farsa ideológica necessária "para se definir o negro

\footnotetext{
${ }^{5}$ Ressaltamos que esta análise se refere a dados coletados em comércios no ano de 2014. Nos últimos anos é notável a circulação de produtos capilares que valorizam os cabelos crespos. Todavia, consideramos que isto não tira a validade da discussão deste trabalho, haja vista que ainda circulam produtos e discursos que contribuem para a dinâmica do racismo na sociedade brasileira.
} 
como inferior, numa estética que, no fundamental, colocava-o de um lado como a negação da beleza e, de outro, como anti-herói [...] animal conduzido por reflexos” (MOURA, 1988, p. 26). O autor acentua que esta produção cultural funcionou para a manutenção do sistema social vigente e atravessa a história até a atualidade. Vale destacar que a literatura contemporânea, embora mais aberta, compartilha com a mídia a manutenção de paradigmas europeizados, atualizando um imaginário racista já existente.

A mídia insiste numa estrutura histórica vinculada "à dimensão corpórea como elemento distintivo entre um eu civilizado e o outro bárbaro" (BORGES, 2012, p. 188). Na Idade Média, espetacularizou-se o que era considerado anormal e disforme, o "outro", no caso, o negro escravizado. A construção da "anormalidade" corpórea do negro era usada como confirmação da retidão e padronização universal do branco europeu superior.

A história do tráfico e escravidão de negros no Brasil atesta essa concepção. Segundo Maestri (1986) e Pinsky (2000), os escravos domésticos eram escolhidos pelo critério de distanciamento da aparência negroide e aproximação do ideal caucasiano. Aliás, Rodrigues (1997) lembra que o "cuidado" com a aparência se iniciava nos barracões da costa africana, onde os negros ficavam à espera do tráfico intercontinental. Os aprisionados eram tratados ali de modo que demonstrassem boa aparência e saúde. Ainda assim, ao chegarem ao Brasil e serem largados nos mercados de escravos, como o Valongo, eram desprezados e vistos como criaturas desumanas. Essa tradição produzia diferença moral a partir da manipulação de corpos fenotipicamente distintos. Reforçava-se a padronização e "superioridade" da estética branca, ao mesmo tempo em que atrelava-se o negro ao símbolo de selvagem, brutal e animalizado.

Além disto, Maestri (1986) relata que a aparência do negro influenciava em sua alforria, pois os negros "mais brancos" eram libertos mais facilmente. Mas, no cotidiano daqueles que permaneciam cativos, o corpo era oprimido de tal forma que, por exemplo, não se negava cortar a mão ou o braço para evitar a perda de um escravo para as prensas da moenda de cana. O trato inferiorizante delegado à subjetividade negra esteve sempre ligado à corporeidade, imprimindo a ideia de subalternidade humana, cultural, espiritual, física, social, econômica, epistemológica, biológica etc. por meio do maltrato físico.

Em linhas gerais, os relatos históricos indicam que, usado como força equivalente à de animais, o corpo negro era visto de formas distintas. Para os traficantes, o negro era peça de troca 
e fonte de renda (RODRIGUES, 1997); para os senhores, as mulheres negras eram objetos de prazer sexual e promessa de cura de doenças sexualmente transmissíveis, como a sífilis, por meio da relação sexual (CHIAVENATO, 1987; PEREGALLI, 1988); para a sociedade escravista como um todo, o sujeito negro (corpo, intelecto e espírito) era radicalmente inferior e aceitavelmente punível por sua corrupção moral, espiritual e física (MAESTRI, 1986; PEREGALLI, 1988). Entretanto, por distintas que sejam essas e outras imagens do negro, têm todas base na crença produzida sobre um “outro" desviante, marcado pela diferença e conceituado como aberração à normalidade da brancura.

A exposição da corporeidade negra como distal da humanidade vista como ideal, como se percebe em muitos produtos estéticos atuais, é uma estratégia histórica de promoção do racismo. Um caso específico disso, de acordo com Borges (2012), foi a exibição do corpo de Saartjie Baartman, mulher negra que possuía as nádegas avantajadas (na verdade, tinha o que agora se reconhece como esteatopigia), bem como os lábios vaginais alongados. Baartman recebeu o nome de Vênus Hatentote para ser exposta em toda a Europa como protótipo da "não-humanidade", da anormalidade negra e estudada pela ciência intencionalmente racista.

Segundo Borges (2012), a partir deste episódio, construiu-se uma ideia universal sobre a mulher negra: presa a um corpo anormal, pertencente a uma categoria desviante, naturalmente hipersexualizada, sem domínio de si e devassa, expressão da depravação de uma moralidade sexual, aceita apenas como objeto de prazer libidinoso de outro. A realidade imagética atual contribui para rememorar esta imagem histórica e assim tipificar a mulher negra como inferior e desviante do padrão étnico da mulher branca, que é considerada bela, em oposição à negra, construída como inferior.

O uso constante da imagem da mulher negra como estética desviante nos leva a Carneiro (2003), que ressalta que, nos processos de colonização, “a apropriação sexual das mulheres do grupo derrotado é um dos momentos emblemáticos de afirmação de superioridade do vencedor" (CARNEIRO, 2003, p. 49). No Brasil, a violência sexual afirmada na Colônia baseia as hierarquias de raça e gênero presentes ainda hoje na sociedade, fixando padrões de beleza excludentes. A autora destaca que as "mulheres negras fazem parte de um contingente de mulheres que não são rainhas de nada, que são retratadas como antimusas da sociedade brasileira, porque o modelo estético de mulher é a mulher branca." (CARNEIRO, 2003, p. 50). 
Numa análise mais detida sobre essa afirmação, nota-se que a mulher negra não é “apenas” considerada inferior, mas é representada como inimiga da beleza, é o mal encarnado na “antibeleza", a corrupção do padrão, o desvio, o erro, o pecado, o mal não apenas técnico, mas moral. Antimusa, imprime a ideia do oposto da perfeição estética da musa, e, por isso, a degradação mais completa, o polo contrário da beleza - a feiura.

Nesse contexto, pode-se interpretar, ao menos parcialmente, uma das motivações para a existência de alguns produtos de beleza direcionados para a mulher negra. Ao consumir o produto e sua ideia, ao "alisar e relaxar" os cabelos, a mulher negra parece esforçar-se para um esvaziamento de seu corpo, para a retirada de um mal que é expresso pelos traços físicos como pele, cabelo, nariz e lábios. O alisamento do cabelo é uma forma de retirar de si o estado de antimusa e - analogamente a um ditado popular - arrancar o mal pela raiz (do cabelo!).

Para Peregalli (1988), a concepção medieval de que o corpo era instrumento do pecado foi transferida para a concepção do corpo negro, justificando os sofrimentos físicos, que deviam ser aceitos como remissão de pecados e degraus para a chegada ao céu. "A submissão total do corpo significava a libertação total da alma" (PEREGALLI, 1988, p. 22). Submeter o corpo negro à culpa do pecado e ao preço pago por ele é uma estratégia eficaz, pois as características estéticas deste o diferenciam veementemente do corpo branco. O corpo é então utilizado como uma ferramenta a mais na legitimação da opressão existente.

Se a violência era um modo de libertar a alma do negro, era, ao mesmo tempo, uma forma de "branqueá-lo", ou seja, de aproximá-lo da "pureza" branca. No mesmo sentido, o uso de produtos de beleza que aproximam a mulher negra do padrão da mulher branca pode ser compreendido como um meio de libertar o corpo dos "pecados" e do "mal" original que se considera ser gente negra. É como se tais produtos cumprissem a função simbólica e difundida que tinham os chicotes e os troncos da época escravista: purificar o negro de seus pecados, libertar a alma pela sujeição à opressão ocidental, converter-se de um estado naturalmente pecaminoso e escuro para outro de pureza e brancura.

O conceito de mal presente no corpo negro é compreendido por Malachias (2007) a partir da discussão sobre os termos populares "cabelo bom" e "cabelo ruim". Para a autora, a cultura ocidental tipificou os cabelos diferentes conforme interesses das relações de poder no campo social. 
A oposição bom/ruim esconde tensões presentes na sociedade brasileira e difundidas pela denominação capilar hierárquica.

Malachias (2007) pontua em tons fortes: "O bem é virtude. O mal é defeito. Ser bom também remete a valores como honestidade, justiça, solidariedade, enquanto ser ruim (ser mau) provoca a aversão, medo, repulsa, dor, insatisfação" (MALACHIAS, 2007, p. 37). A oposição bondade/maldade, ganha conotação moral e religiosa, dada a tradição advinda do maniqueísmo, em que o bom é bem, representado pela brancura, e o ruim é mal, representado pela escuridão.

A autora ressalta que, num imaginário racista, por detrás “da ideia do mal, estariam os candomblés e seus sacerdotes - ialorixás e babalorixás. De forma objetiva e também subliminar, a cultura negra é associada à ruindade e ao “diabo"” (MALACHIAS, 2007, p. 38). Os cabelos, como configuração expressiva do pertencimento étnico-racial, simbolizariam a marca do bem ou do mal essencial, espiritual e ao mesmo tempo corpóreo e sobrenatural: se é liso, característico do branco, é bem; se é crespo, característico do negro, é mal.

Desse modo, os sentidos de cabelo bom/ruim presentes no vocabulário popular, para além de diferenciações tecnicamente estéticas, sustentam e legitimam pejorativamente a hegemonia branca instaurada no Brasil ao custo da opressão contra a corporeidade negra. Ter características fenotípicas de negro (cor da pele, espessura dos lábios, formato do nariz, textura capilar) torna o sujeito sem valor positivo, feio, ao contrário do branco que é classificado como bonito (MALACHIAS, 2007). Mais do que isso, a expressão "cabelo ruim" se insere num contexto mais amplo - mesmo que muitas vezes isso não seja perceptível - em que há a tentativa de minar a humanidade da negra e do negro e atribuir a estes um caráter demoníaco sob as custas de discriminar religiões de matriz africana.

Afinal, o pertencimento étnico-racial do negro é declarado por seu fenótipo e seus sinais diacríticos principais que, conforme Gomes (2008), são a cor escura da pele e o cabelo crespo. É por esse motivo que ambos estão conectados no processo de rejeição/aceitação do corpo e da identidade negra. Segundo Gomes (2008), aprende-se durante toda a vida e nas diversas instâncias sociais o que é o sujeito negro. O olhar social compara os indivíduos a partir do padrão estético branco, considerado o ideal. Em Sodré (1986), fica evidente que esse olhar social foi construído historicamente em meio à sociedade capitalista ocidental, o que explica a padronização da 
comparação estética. Gomes (2008) argumenta que a sociedade hierarquiza a partir de tal comparação, minimizando o valor do sujeito negro por seus sinais diacríticos - corpo e cabelo.

Os sujeitos, por sua vez, buscam reconhecimento e podem assimilar a ideia de dever aproximar-se do padrão social ou mesmo resistir a esta. O primeiro caso, destaca Gomes (2008), é o mais problemático, bem como o mais aceito. A negação de si mesmo marca a história da negra e do negro na sociedade brasileira, e desvela o enraizamento do problema: a existência humana, ou a negação da mesma quando se refere ao sujeito afrodescendente, capturado de seu território original sob a falácia de não ser gente.

A “acusação de sujeira física, moral e da 'alma' tem sido historicamente imputada ao corpo do negro e da negra" (GOMES, 2008, p. 140), naturalizando a imagem de que o descuidado com o corpo e o cabelo e o cheiro de suor são naturais nos negros. Por isso, a brancura tornou-se um padrão e um desejo universal, que rege a busca identitária dos sujeitos. O alisamento e o relaxamento dos cabelos crespos revelam-se, por vezes, como descontentamento com a aparência própria e obsessão por alcançar o branqueamento. O que não pode ser afirmado é que sempre que uma mulher negra ou um homem negro alisa o cabelo está demonstrando a introjeção do ideal branco, pois essa é uma escolha pessoal e aceitável, desde que seja consciente e não resultado da imposição estética.

De fato, para o negro, a "rejeição do cabelo, muitas vezes, leva a uma sensação de inferioridade e de baixa auto-estima" (GOMES, 2008, p. 189), já que se polarizam os extremos de cabelo crespo/liso, como desejável e indesejável, sendo o crespo aquele que tem menor valor na hierarquia social e na estética.

No imaginário social "quanto mais crespo for o cabelo, mais próximo o sujeito que o possui estará de um grupo étnico/racial ainda considerado inferior, tanto no sentido biológico quanto cultural.” (GOMES, 2008, p. 216). Essa hierarquização social a partir de padrões estéticos advém do século XV, quando se construiu um padrão hegemônico de beleza baseado na Europa, classificando a aparência física com valor positivo ou negativo. A expressão "cabelo ruim” e outras derivadas (“cabelo de Bombril”, “pixaim”, “Assolan”, “esponja de aço”, “bucha”), além de ser diretamente agressiva, é uma estratégia discursiva de rememoração da ideia de que a corporeidade negra é habitação do mal. Assim, demarcam-se espaços aceitáveis para os sujeitos que possuem 
cabelo crespo, revelando quão entranhado o racismo está nas concepções compartilhadas pela sociedade brasileira.

Além disso, no que concordam Carneiro (2003) e Malachias (2007), a negativação da imagem do negro é a negação do sujeito mesmo, o que dificulta o exercício da cidadania plena obtida no usufruto do respeito à diversidade. Os direitos humanos desses sujeitos existem legalmente, mas a classificação social baseada na cor cria a segregação do acesso aos mesmos, pois o negro é considerado um desviante, enfim, um subumano.

Em última análise pode-se afirmar que o julgamento estético dos sujeitos, com todas as reverberações inferidas, revela não uma estética valorizadora da diversidade, mas uma estética do racismo, uma estética que nega a diferença e é aceita como natural, compartilhada no imaginário social e difundida por diversos meios, como as imagens de produtos de beleza presentes em comércios do nordeste goiano.

$\mathrm{Na}$ realidade, trata-se de uma estética que esconde a ética racista (paralela à sexista, à classicista, etc.), que ainda baseia a sociedade capitalista. Assim, alijam-se os sujeitos da possibilidade de divergir, de desfrutar de seus direitos concretos e simbólicos. Ao mesmo tempo, legitima-se a "bondade" do sistema social vigente e perpetua-se o mesmo, permanecendo a crença da existência de uma "democracia racial" no Brasil. Portanto, as reflexões aqui realizadas apontam para uma implicação política da difusão de estereótipos contra o negro e a negra na rede midiáticopublicitária.

A partir desse imaginário social racista, tornam-se normalizadas as ofensas corriqueiras a sujeitos negros comuns, nas escolas, no trabalho, nas ruas, nas famílias. A sociedade que se apresenta resoluta contra o racismo exposto na mídia não demonstra, na maioria das vezes, a mesma ênfase por combater comportamentos discriminatórios contra a gente negra em geral - o preconceito racial permanece tão corrosivo quanto socializável; é a estética do racismo camuflando uma ética excludente.

\section{Considerações finais}

O nordeste goiano tem maioria negra, além de abrigar o Quilombo Kalunga, o que não impede a minimização da imagem dessa população nos diferentes aportes midiáticos, mesmo nos comércios locais. Isso é explicado ao compreender-se que estes se reportam a uma rede midiático- 
publicitária mais ampla. Nessa rede, a imagem tem papel central de difusão de sentidos, sendo possível analisá-la de modo contextualizado.

Assim, foi possível constatar que a imagem da mulher negra nos produtos de beleza encontrados nos comércios pesquisados carrega o estereótipo da desvalorização estética, centrado especialmente na negativação do cabelo crespo. Esse estereótipo foi construído social e historicamente no imaginário brasileiro e refere-se a uma série de argumentos que tentam justificar a inferiorização do sujeito negro a partir do julgamento negativo, estético e moral sobre seu corpo.

Pode-se falar de uma estética do racismo, que camufla uma ética racista de efeitos reais na opressão étnico-racial concreta e simbólica. A estética do racismo esconde que os conceitos de cabelo bom/ruim, sujeito feio/bonito, ligados ao pertencimento étnico-racial, não são naturais, repercutem a dominação histórica de brancos sobre negros e causam prejuízo social a distintos indivíduos. Ao minar a autoestima do sujeito negro e naturalizar estereótipos, preconceitos e discriminação na sociedade, a estética-ética do racismo segrega, legitima a ordem social vigente e destitui os indivíduos do exercício de seus direitos sociais, como, por exemplo, o direito à diversidade respeitada. Logicamente, ao minar a autoestima das pessoas negras, o desenvolvimento social sustentável é basilarmente comprometido, principalmente nos casos em que a maioria populacional é negra, como no nordeste de Goiás e no Brasil.

Toda a problemática levantada baseia-se na imagem do negro deteriorada por julgamentos estéticos hierarquizados e argumentos históricos tendenciosos. Portanto, para ressignificar a imagem desse sujeito e empoderá-lo, é preciso atuar ao menos nas vias da estética e da história. Isto é, reconhecer, conhecer, aceitar, valorizar e se relacionar com o corpo, com a cultura, com a história, com o pensamento negro, africano e afro-brasileiro, a desconstruir mitos históricos e positivar a imagem do negro e da negra.

É urgente criar possibilidades de superação do atual estado subjugado da imagem da negra e do negro por meio do protagonismo desses sujeitos. Este artigo contribui ao dar voz à discussão sobre a construção de um imaginário racista que pode influenciar na interação dos sujeitos em diversos espaços sociais não apenas no nordeste goiano, mas em todo o Brasil. Desconstruir representações negativas sobre as pessoas negras não é um processo simples, tampouco fácil, haja vista que as relações sociais estão entremeadas pelo racismo enquanto construção histórico-cultural bastante complexa e difusa. 
Nessa era do capitalismo cada vez mais abstrato, parece não haver um centro de produção de concepções preconceituosas, que poderia ser finalmente desarmado. É evidente que existem instâncias com maior ou menor influência de socialização das concepções etnocêntricas, como a rede midiático-publicitária que hoje alcança massiva e redundantemente a população brasileira. Entretanto, justamente por atuar a nível simbólico, a ética racista não é palpável, mas, ao mesmo tempo, é compartilhada, enredada no cotidiano dos indivíduos, o que complexifica, mas não impede, sua superação.

Frente à problemática difusão de estereótipos negativos sobre a negra e o negro por meio de imagens, considera-se necessário caminhar junto à descolonização epistemológica proposta por autores como Santos (2009), ampliando a abrangência desta ao que poderia ser chamado de "descolonização estética". Isso significa produzir e difundir alternativas subversivas à estética tipificada com norma na brancura, representar positivamente a pessoa negra por meio de imagens em diversos espaços sociais, midiáticos ou não, como a escola, por exemplo. A educação pode atuar por meio da inserção da presente problemática na formação inicial e continuada dos docentes do nordeste goiano e do Brasil, bem como nas escolas. Isso exigirá a revisão e a reinvenção individual e coletiva das bases da sociedade e das organizações nela presentes.

Combater o "racismo nosso de cada dia", portanto, exige mais que recursos discursivos em prol da igualdade. Com atuação no imaginário social, o racismo tem de ser enfrentado por meio da construção concreta e simbólica de um imaginário menos preconceituoso, começando pela abertura basilar a novos paradigmas, filosofias, estéticas, narrativas, vozes e sujeitos que possibilitem a desconstrução da referência na unicidade na mesma medida em que contribuam para uma ética da diversidade.

\section{Referências}

BARRETO, Roberto Menna. Análise transacional da propaganda. São Paulo: Summus, 1981.

BAUMAN, Zygmunt. Vida para consumo: a transformação das pessoas em mercadorias. Trad. Carlos Alberto Medeiros. Rio de Janeiro: Jorge Zahar, 2008.

BORGES, Rosane da Silva. Mídias, racismos e representações do outro: ligeiras reflexões em torno da imagem da mulher negra. In: BORGES, Roberto Carlos da Silva; BORGES, Rosane. Mídia e racismo. Brasília, DF: ABPN, 2012. 
BRASIL. Ministério da Educação. Uma história do povo Kalunga. Brasília: MEC; SEF, 2001.

CARNEIRO, Sueli. Enegrecer o feminismo: a situação da mulher negra na América Latina a partir de uma perspectiva de gênero. In: Ashoka Empreendedores Sociais e Takano Cidadania. Racismos contemporâneos. Rio de Janeiro: Takano, 2003.

CHIAVENATO, Júlio José. O negro no Brasil: da senzala à guerra do Paraguai. 4. ed. São Paulo: Brasiliense, 1987.

FREIRE, Paulo. Pedagogia da autonomia: saberes necessários à prática educativa. 49. ed. Rio de Janeiro: Paz e Terra, 2014.

GOMES, Nilma Lino. Sem perder a raiz: corpo e cabelo como símbolos da identidade negra. 2. ed. Belo Horizonte: Autêntica, 2008.

IBGE. Goiás: Campos Belos: censo demográfico 2010: resultados do universo características da população e dos domicílios. IBGE, 2010b. Disponível em: $<\mathrm{http} / /$ www.cidades.ibge.gov.br/xtras/temas.php?lang=\&codmun=520490\&idtema=67\&search= goias|campos-belos|censo-demografico-2010:-resultados-do-universo-caracteristicas-dapopulacao-e-dos-domicilios-> Acesso em: 09 de abril de 2014 às 22h:56min.

IBGE. Goiás: Monte Alegre de Goiás: censo demográfico 2010: resultados do universo características da população e dos domicílios. IBGE, 2010a. Disponível em: $<\mathrm{http} / / \mathrm{www}$. cidades.ibge.gov.br/xtras/temas.php?lang=\&codmun=521350\&idtema=67\&search= goias|monte-alegre-de-goias|censo-demografico-2010:-resultados-do-universo-caracteristicas-dapopulacao-e-dos-domicilios-> Acesso em: 09 de abril de 2014 às 22h:54min.

KELLNER, Douglas. A cultura da mídia - estudos culturais: identidade e política entre o moderno e o pós-moderno. Trad. Ivone Castilho Benedetti. Bauru, SP: EDUSC, 2001.

LÜDKE, Menga; ANDRÉ, Marli. Pesquisa em educação: abordagens qualitativas. 8. reimp. São Paulo: EPU, 2004.

MAESTRI, Mário. Breve história da escravidão. Porto Alegre: Mercado Aberto, 1986.

MALACHIAS, Rosangela. Cabelo bom. Cabelo ruim. São Paulo: NEINB, 2007.

MOURA, Clóvis. Sociologia do negro brasileiro. São Paulo: Ática, 1988.

OLIVEIRA, Dennis de. Etnomídia: a construção de uma paisagem étnica na linguagem midiática. In: BATISTA, Leandro Leonardo; LEITE, Francisco (orgs.). O negro nos espaços publicitários brasileiros: perspectivas contemporâneas em diálogo. São Paulo: Escola de Comunicações e Artes/USP, 2011.

PEREGALLI, Enrique. Escravidão no Brasil. São Paulo: Global, 1988.

PEREIRA, Edimilson de Almeida; GOMES, Núbia Pereira de Magalhães. Ardis da imagem: exclusão étnica e violência nos discursos da cultura brasileira. Belo Horizonte: Mazza Edições: PUC Minas, 2001. 
PINSKY, Jaime. A escravidão no Brasil. 17. ed. São Paulo: Contexto, 2000.

RAMOSE, Mogobe B. Globalização e Ubuntu. In: SANTOS, Boaventura de Sousa; MENESES, Maria Paula (orgs.). In: SANTOS, Boaventura de Sousa; MENESES, Maria Paula (orgs.). Epistemologias do sul. Coimbra: Almedina, 2009.

RODRIGUES, Jaime. O tráfico de escravos para o Brasil. São Paulo: Ática, 1997.

SANT'ANA, Jonathas Vilas Boas de. A representação da pessoa negra em imagens de comércios do nordeste goiano. Revista Urutaguá (online). n. 31, nov. 2014/abr. 2015, p. 41-54, 2015.

SANTAELLA, Lucia. Semiótica aplicada. 2. reimpr. São Paulo: Pioneira Thomson Learning, 2005.

SANTOS, Boaventura de Sousa. Para além do pensamento abissal: das linhas globais a uma ecologia de saberes. In: SANTOS, Boaventura de Sousa; MENESES, Maria Paula (orgs.). Epistemologias do sul. Coimbra: Almedina, 2009.

SILVA, Nelson Fernando Inocencio da. Consciência negra em cartaz. Brasília: UnB, 2001.

SODRÉ, Muniz. Reinventando a educação: diversidade, descolonização e redes. 2. ed. Petrópolis, RJ: Vozes, 2012.

SODRÉ, Muniz. Televisão e psicanálise. São Paulo: Ática, 1987. 